\title{
Design Directed Learning in Chemical and Biochemical Engineering
}

\author{
Anand Prakash \\ Associate Professor \\ Chemical and Biochemical Engineering Department \\ The University of Western Ontario \\ London, Ontario, Canada N6A 5B9 \\ aprakas2@uwo.ca
}

\begin{abstract}
Design involves finding solution to identified needs or problems in the real world. Thus learning through design makes the students appreciate greatly the theoretical knowledge they acquired in other engineering courses. Integration of engineering science, technology and communication skills is one of the main goals in the design practice. The author believes that practice of engineering through a design directed approach is more efficient compared to problem based approach. The fourth year capstone design course is a full year course in author's department through which the students are exposed to various aspects of process and equipment design in chemical and biochemical industry. Regular weekly meetings and preparation of reports at different phases of design prepare the students for the challenges of real world. The students work together in a team practicing time management, brain storming, and helping each other throughout the project. During regular meetings with instructors and industry consultants, students learn to apply engineering and professional judgement and propose solutions to open-ended design problems. They are encouraged to evaluate design alternatives and demonstrate initiative in applying innovative solutions. Involvement of consultants from the industry improves students participation and has better impact on their performance. They identify safety, environmental, and economic issues, and their impact on design decisions in all phases of the design. Oral presentations are required and formally evaluated by judges from academia and industry and feedback provided. A formal design report is submitted at the end of the year also lists the improvements made in design based on feedbacks from progress reports and presentations.
\end{abstract}

\section{Introduction}

Design problems are inherently open-ended and generally vary by industry and plant type. Developing the right solution requires searching for possible solutions. A search strategy must include devising alternative solutions and analyzing them to find the "best" solution to the problem. This involves locating, collecting, analysing and integrating required information. This requires students to become sophisticated consumers of information. There is need to access information from a variety of sources such as government reports, journals, World Wide Web (WWW), industry consultants etc. The role of Web is of course becoming increasingly important in the learning environment of these projects. However, for effective use of this information source, there is need to provide meaningful context and learning goals [1](Brown et al., 1988).

Open-ended learning environment of project-based courses capstone design present a multitude of unique learning issues. Such courses introduce more cognitively complex tasks into classrooms [2]. Through variety of approaches and technology options, the students are enabled to work on tasks that require critical thinking, self direction, problem solving, or meaningful integration of knowledge[3][4].

\section{Capstone Design Project}

In capstone design projects engineering students get an opportunity to integrate the knowledge and skills acquired in earlier courses while applying them to find a solution to a real world problem or a need. The solution must be developed to meet simultaneously the demands of several stakeholders - customers, investors, employees and regulatory agencies. Failure 
in design can become the target of investigation by government agencies, journalists and citizens.

The emphasis of the capstone design in our department is to develop professional and engineering judgment skills of the students through a relatively involved design exercise. The course has all the characteristics of an open-ended learning environment. The students work in teams to develop design of a selected chemical or biochemical process. The design exercise involves process analysis and synthesis equipment sizing through creative problem solving with considerations of cost, safety, social and legal issues. The general objectives are for the students to become able to:

- apply engineering and professional judgement to propose solutions to open-ended design problems.

- formulate problems and apply decision making to evaluate design alternatives.

- identify safety, environmental, social, legal and economic issues, and their impact on design decisions.

- develop strong technical communication skills in order to present and defend technical information and design decisions in both written and oral format.

- recognize the need for continual (life-long) learning to keep abreast of new developments and information that could affect decisions related to design, modifications and improvements in chemical processes.

These objectives are accomplished within the framework of a workshop, simulating to the extent possible, and the real world industrial environment. During the workshops, groups of up to six students are given guidance and coaching (directed and interactive learning) to assist in moving forward the design project.

\subsection{Projects Topic Selection}

At the beginning of the academic term, a list of project topics is compiled by the course coordinator. The project topics are selected from different areas such as renewable energy and fuels, heavy oil upgrading, pharmaceuticals and fine chemicals, and environmental pollution control. Usually about half of the project topics originate from industry. Initial information including background and feed/product specification is made available. An example of one such project background information is given below.

\subsubsection{Project background - an example}

Acidic leachate, also called the acidic mine drainage (AMD), is recognized as the largest single environmental problem facing the mining industry. Oxidation and leaching of sulphide minerals in the mines and in mineral wastes can produce an acidic water which contains high concentrations of metals, toxic elements and sulphuric acid. This acidic leachate is one of the major causes of chemical pollution in the mining and mineral processing. Typically, the first impact of the AMD is on the aquatic ecosystem by sulphuric acid present in the groundwater and surface runoffs. This activity would eventually destroy the aquatic organisms and vegetation along waterways if it is not controlled. The longer-term problem arises from the heavy metals and toxic elements present in waterways. The accumulation of these metals in animals and humans through the food chain would be dangerous to their lives.

Conventional acidic leachate treatment process involves neutralization and aeration. The resulting suspension is separated into treated water effluent and a concentrated sludge using a solid-liquid separation system. The treated water is discharged if it meets the discharge standard. Several criteria for treated-water quality have been employed depending on the geographical location and the end-use, although drinking water standards are being considered in recent years. The sludge containing metals can be either recycled/reused or disposed of.

The goal of this design project is to develop treatment-technology options to treat acidic leachate generated from copper/zinc mining/milling operations. Two treatment options may be considered. One is based on conventional acidic leachate treatment process involving neutralization and aeration. The other option may include advanced technologies such as chemical precipitation using different precipitants, ion exchange, membrane separation (e.g., reverse osmosis), freeze crystallization and biotechnology, etc. The project will compare the two treatment options (conventional and advanced) on the basis of technical merits and economic benefits.

\subsection{Project Scheduling and Task Breakdown}

The development of a chemical process design project can be quite complex and overwhelming for the young students. Therefore, they are provided with a framework and a list of tasks with their format, deadlines and milestones to allow the students to 
budget time and develop a schedule. Deadline refers to date and time a report is due (for marking) or task is to be finished while milestone gives suggested date to finish a task to stay on schedule.

They are further advised to divide the task into subtasks among the team members with specified responsibilities. The main tasks to be completed for the design project are listed in Table 1 and 2 for each term. The interdependence of the tasks is pointed out to prepare a project schedule in the form of a Gantt chart.

Table 1. First term tasks

\begin{tabular}{|c|l|c|}
\hline $\begin{array}{c}\text { Task } \\
\#\end{array}$ & \multicolumn{1}{|c|}{ Title } & $\begin{array}{c}\text { End } \\
\text { date }\end{array}$ \\
\hline 1 & Project Proposal or stake-out & $\$$ \\
\hline 2 & Detailed Process Flow Plan & $\$$ \\
\hline 3 & $\begin{array}{l}\text { Material \& Energy Balances and } \\
\text { Process Simulation }\end{array}$ & \\
\hline 4 & Standard Equipment sizing & $\$$ \\
\hline 5 & First formal presentation & $\$$ \\
\hline 6 & First formal report & \\
\hline
\end{tabular}

Table 2. Second term tasks

\begin{tabular}{|c|l|c|}
\hline $\begin{array}{c}\text { Task } \\
\#\end{array}$ & \multicolumn{1}{|c|}{ Title } & $\begin{array}{c}\text { End } \\
\text { date }\end{array}$ \\
\hline 1 & Short-cut equipment design & $\$$ \\
\hline 2 & Detailed equipment design & \\
\hline 3 & Safety and hazard analysis & \\
\hline 4 & Environmental impact analysis & \\
\hline 5 & Process economics & $\$$ \\
\hline 6 & Second formal presentation & $\$$ \\
\hline 7 & Final formal report & $\$$ \\
\hline
\end{tabular}

The course website gives detailed format for each task with appropriate examples and check points. Two of these tasks- one from each term-are discussed below in a few more details.

\subsubsection{Project proposal - task \# 1}

This is the first task of the project and it helps bring the team members together. A format for the task is provided consisting of following main sections.

I. Objectives of the project

II. Background (brief) and need analysis

III. Plant capacity and location.

IV. Process selection/creation with feed and product specifications

V. A project schedule (time line) with milestones and deadlines.

The students conduct directed search of project topic background, collect and analyse information using skills from math and statistics to justify need for the facility. They get direction while making decisions for capacity and location based on business considerations. The need for a new process is often identified based on market potential or a service requirement due to one or more of the following reasons:

\section{Demand for a new product}

Potential for an improved (value added) product

Growing demand for an existing product

$>$ New more efficient process to reduce cost of manufacture

New environmental regulations

\subsubsection{Short-cut equipment design}

For the equipment design task, the students first go through a short-cut design exercise for the selected piece of equipment before a more involved detailed design is developed. They are guided to select appropriate procedure and use justifiable approximations to arrive at a quick sizing of the equipment. This exercise helps with evaluation of alternatives or options, and with preliminary cost estimations. This task helps students develop/enhance the following important skills set.

- Engineering judgment

- Critical thinking

- Deductive reasoning 
The tasks requires a systematic evaluation of alternative solutions. Possible alternatives or options for the application are listed and the options are evaluated based on selected set of criteria. The choice may be between different types of equipment for the required service (e.g. rotary vs. fluidized bed dryer) or different configurations of same equipment type (e.g. vertical vs. horizontal vapor-liquid separator). The differences between alternatives are discussed and illustrated with diagrams. For a more detailed and systematic evaluation of alternatives, the students are directed to select a set of applicable criteria similar to one given below and use a ranking method to arrive at the final decision.

$>$ Technical maturity

$>$ Flexibility

$>$ Environmental impact

$>$ Safety and control

$>$ Availability of space (possible constraint)

Table 3 below illustrates the ranking method. The students are provided guidelines to assign scores for different criteria based on practical considerations and engineering judgement. Depending on the nature of the problems, more than one level of evaluation can be conducted. From the ranking in Table 3, option \# 3 seems to be a better choice. If the score are too close say within 3\% (statistical dead heat!), a directed decision is arrived at based on discussions with the advisor and industry consultant.

After the short-cut design, the students develop a more detailed design of the selected piece of equipment which will demonstrate a deeper understanding of it design (including internals), operational, control and safety issues.

Table 3. Ranking of options based on selected criteria (scale of 1 to 10 )

\begin{tabular}{|c|l|c|c|c|}
\hline & Criteria & $\begin{array}{c}\text { Option } \\
\mathbf{\# ~ 1 ~}\end{array}$ & $\begin{array}{c}\text { Option } \\
\mathbf{\# ~ 2}\end{array}$ & $\begin{array}{c}\text { Option } \\
\mathbf{\# ~ 3}\end{array}$ \\
\hline 1 & $\begin{array}{l}\text { Technical } \\
\text { Maturity }\end{array}$ & 8 & 5 & 7 \\
\hline 2 & Flexibility and & 7 & 7 & 9 \\
\hline 3 & $\begin{array}{l}\text { Safety } \\
\text { Control }\end{array}$ & 7 & 7 & 7 \\
\hline 4 & $\begin{array}{l}\text { Environmental } \\
\text { Impact }\end{array}$ & 5 & 8 & 6 \\
\hline 5 & Space & 4 & 7 & 7 \\
\hline 6 & Cost & 8 & 5 & 7 \\
\hline & Score (\%) & $\mathbf{6 5}$ & $\mathbf{6 5}$ & $\mathbf{7 2}$ \\
\hline
\end{tabular}

\section{Challenges of the Course}

The course presents significant challenges to both students and instructors. Since the design projects require application of concepts from different courses such as thermodynamics, fluid mechanics, heat transfer, mass transfer etc. and their integration, a good level of grasp of various concepts is required. While concepts are often introduced using simpler examples, most of the real world design problems are quite complex in nature, requiring additional efforts from both sides. The problem is further exasperated due to open ended and ill-defined nature of the design problems and different and sometimes conflicting information from different sources.

The students are also expected to take to a higher level their skills in math and usage of computer software (e.g. Excel, Process Simulators). At the same time they are trying to come to grips with issues such as reasonable approximation and estimation, degree of uncertainty in a solution and balance between uncertainty and precision in reported results.

\section{Examples of Comments from Students}

\section{Generally positive comments}

"The course was a wonderful experience and opened our eyes into what the industry is like"......

"Although a lot of work this course was probably the most enjoyable class I have taken at Western and would like to thank you all for helping us out so much"

"This course made me feel like an engineer for the first time"

\section{Negative comments}

"The course itself is quite difficult. An enormous amount of work is required at the beginning of the year, it was difficult to know what was required and very overwhelming"

"Too much work and too many assumptions - it should be ensured that projects chosen have data available"

"The course would be more beneficial to students as a learning experience if the students were given more instructions on the choosing of the topics in order to 
ensure that the projects are reasonable and acceptable for the experience level of the students......"

\section{Accolades}

Over the last eight years, students design teams from the course have won three first place prizes, one second and two third place prizes at the SNC Lavalin Plant Design Competition held by the Canadian Society for Chemical Engineers every year for Canadian Universities

\section{References}

[1]J.S. Brown, A. Collins, and P. Duguid, "Situated cognition of learning", Educational Researcher, (1988), 18, pp. 32-42.

[2]P.C. Blumenfeld, E. Soloway, R.W. Marx, J.S. Krajcik, M. Guzdial, and A. Palincsar, "Motivating project-based learning:Sustaining the doing, supporting the learning", Educational Psychologist, (1991), 26, pp. 369-398.

[3]B.A. Greene, "Comprehension of text in an unfamiliar domain: Effects of instruction that provides either domain or strategy knowledge" Contemporary Educational Psychology, (1995), 20, pp. 313-319.

[4]M. Hannafin, C. Hall, S. Land, and J. Hill, "Learning in an open-ended learning environment: Assumptions, methods, and implications", Educational Technology, (1994), 34(8), pp. 48-55. 